\title{
O Ensino das Soluç̧ões Aquosas de Electrólitos a Nível Secundário \\ Parte II - Uma Proposta para o Ensino do Fenómeno da Condução Eléctrica em Soluções Aquosas
}

\author{
A L C INDA L. RIBEIRO*
}

Na parte I fez-se uma análise aos manuais para o ensino secundário no que concerne ao estudo das solucões de electrólitos. Na parte II propõe-se um texto para o ensino dessa matéria para aquele nivel escolar.

\section{INTRODUÇÃO}

Uma vez que o tema da conducão eléctrica em soluções de electrólitos é tratado em termos qualitativos, tanto no $8^{\circ}$ ano de escolaridade como na componente física da disciplina de Físico-Química do $10^{\circ}$ ano, consideramos que será vantajoso nos anos terminais do ensino secundário, antes do estudo das reaç̧ões ácidobase, desenvolver com maior aprofundamento científico o fenómeno da condução eléctrica em soluções aquosas, fornecendo-lhe a descrição quantitativa, aspecto que está ausente no actual programa. Este estudo quantitativo requererá o recurso a actividades experimentais, tendo o aluno a oportunidade de proceder à montagem de dispositivos experimentais e à utilização de instrumentos de medida bem como ao cálculo matemático, aspectos essenciais a uma disciplina como a química.

Seleccionámos um conjunto de conceitos que consideramos essenciais no estudo do fenómeno da condução eléctrica em soluções. Dado o elenco de conceitos e factos que o aluno terá de ter já adquirido, assim como o nível de capacidade de abstracção exigido, o texto apresentado dirige-se a alunos dos anos terminais do ensino secundário.

Apesar do maior aprofundamento com que o tema é abordado nesta proposta relativamente ao que está estabelecido actualmente no programa do ensino secundário. pensamos que da forma como os conceitos estão sequenciados, eles se articulam perfeitamente com o conhecimento que o aluno já possui nesta fase de instrução, havendo uma continuidade com outros as- suntos já estudados pelo aluno. Consideramos que os conceitos escolhidos fornecem a base necessária para uma posterior e mais aprofundada abordagem a esta matéria ao nível do ensino superior.

Tentamos, sempre que possível, partir da observação de factos experimentais para introduzir as noções e fornecer as explicações de acordo com o actual conhecimento.

Convém salientar que não foi nosso objectivo escrever um texto que se inserisse num manual escolar tal como aqui apresentado, mas somente indicar a forma que consideramos correcta para ensinar este assunto. O estilo de escrita final teria de ser coerente com o resto do manual. Também o texto seria ilustrado com figuras que aqui não indicamos por economia de espaço. Conforme dissémos na parte I, textos para alunos devem mostrar bem a distinção entre fenómenos observados e as explicações (teorias) propostas para a sua interpretação. Também por economia de espaço, não temos aqui essa preocupação, pois obviamente o leitor do presente artigo conhece bem essa distinção.

Dado o papel primordial da água como solvente das substâncias mais comuns da vida quotidiana e dado o carácter elementar do texto elaborado, os exemplos apresentados focam sempre as soluções aquosas. Cremos que se o aluno tiver necessidade de estender estes conhecimentos a soluções de outros solventes, fa-lo-á com facilidade desde que estes conhecimentos básicos tenham ficado bem compreendidos.

Indicamos abaixo os pré-requisitos, ou seja, aqueles conceitos, factos e leis que o aluno terá de já possuir nesta fase, a fim de integrar facilmente os novos conceitos no seu esquema conceptual. São indicados, também, os objectivos que se pretende que o aluno atinja.

\section{Pré-requisitos}

Ião; composto iónico; dissolu- ção; dissociação; ionização; extensão de uma reacção; grau de ionização; ácido e base; eléctrodos; condução eléctrica nos metais; resistência eléctrica; Lei de Ohm; circuito eléctrico; amperímetro; fonte de corrente.

\section{Objectivos}

O aluno deve ser capaz de:

1. explicar o fenómeno da condução eléctrica em meios iónicos em termos do movimento, em sentidos opostos, dos catiões e aniões;

2. realizar experiências que permitam identificar uma substância, por ele desconhecida, como electrólito;

3. inferir que a maior ou menor condutibilidade eléctrica de uma solução aquosa depende da quantidade de iões presentes na solução;

4. aplicar correctamente os termos conducência eléctrica e condutibilidade específica;

5. reconhecer a necessidade da definição da grandeza condutibilidade molar;

6. concluir que medidas da condutibilidade eléctrica poderão ser usadas para quantificar o grau de ionizacão de um dado electrólito em água;

7. deduzir as unidades SI para as grandezas estudadas;

8 . reconhecer que a condutibilidade eléctrica de uma solução iónica depende, para além do número de iões presentes, das cargas eléctricas dos iões.

\section{LINHAS GERAIS DO TEXTO DE ENSINO}

\section{A Condutibilidade Eléctrica de Soluções Aquosas}

Num circuito eléctrico como o representado na Fig. 1, a condução da corrente eléctrica faz-se através de condutores metálicos (os fios de ligação), podendo ser a corrente de 


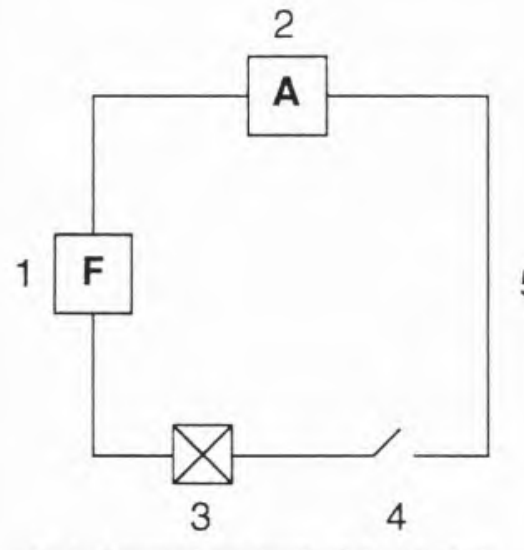

Fig. 1 - Esquema de um circuito eléctrico: 1 - fonte de corrente; 2 - miliamperimetro; 3 - lâmpada; 4 - interruptor; 5 - fios de ligação.

condução interpretada como um movimento ordenado dos portadores de carga - os electrões.

Suponhamos, agora, que a lâmpada existente no circuito anterior é substituída por uma solução aquosa de cloreto de sódio. O contacto eléctrico da solução com os condutores metálicos é estabelecido através dos eléctrodos, os quais são também condutores metálicos. Os eléctrodos têm, neste caso, a forma de placas, podendo ser feitos de um material como a grafite, ou a platina. (Apresentar-se-iam figuras elucidativas).

Verificar-se-á que, também nestas condições, o miliamperímetro inserido no circuito, regista a passagem de corrente eléctrica com uma dada intensidade. Pode concluir-se que a existência da solução aquosa de cloreto de sódio não impediu a condução da corrente eléctrica pelo circuito e, além disso, que a solução aquosa de cloreto de sódio apresenta uma resistência eléctrica, tal como o filamento de uma lâmpada existente no circuito.

A interpretação daqueles fenómenos pode ser feita pressupondo que o cloreto de sódio é um composto iónico, estando os catiões sódio e os aniões cloreto dispostos num determinado arranjo tridimensional (rede cristalina), que é mantido pelas forças de atracção entre os iões de carga de sinal oposto e pelas forças de repulsão entre os iões com carga do mesmo sinal. Quando é adicionado cloreto de sódio à água, verifica-se que o composto iónico se desagrega, passando os iões para o seio da água e obtém-se o que se designa por uma solução aquosa de cloreto de sódio. No decorrer deste processo, designado por dissociação, as moléculas de água são atraídas pelos iões, rodeando-os, impedindo a regeneração do composto iónico. Diz-se que os iões sódio e cloreto na respectiva solução aquosa estão hidratados. (Seriam usadas figuras elucidativas e um estilo que deixasse claro a diferença entre factos observados e respectivas explicações).

A dissociação do cloreto de sódio pode ser apresentada pela equação química

$$
\mathrm{NaCl} \stackrel{\mathrm{H}_{2} \mathrm{O}}{==}=\mathrm{Na}^{+}(\mathrm{aq})+\mathrm{Cl}^{-}(\mathrm{aq})
$$

Coloca-se, agora, uma questão: será que podemos admitir que os iōes presentes na solução aquosa de cloreto de sódio participam na condução da corrente eléctrica?

Para responder a esta questão vamo-nos apoiar no facto de certos iões apresentarem cores distintas, o que permitirá seguir os seus deslocamentos através de uma solução, quando sujeitos à acção de um campo eléctrico. Assim, se estiverem presentes numa solução catiões e aniões que apresentem diferentes cores, e procedendo como indicado na Experiência 1, podemos seguir o sentido dos movimentos destes dois tipos de iões e, consequentemente, ficar a conhecer algumas características do processo da condução eléctrica numa solução iónica.

\section{EXPERIÊNCIA 1}

Título: A condução eléctrica em soluções aquosas. (Naturalmente, apresentar-se-iam figuras elucidativas, e adaptar-se-ia apropriadamente o estilo do texto na descrição e modos de observação destas expe- riências).

Objectivo: Verificar o movimento dos iões positivos e negativos presentes numa solução aquosa, quando a esta é aplicada uma diferença de potencial.

Material: Fonte de corrente contínua; fios de ligacão; crocodilos; vidro de relógio; algodão em rama; água.

Reagentes: Soluções aquosas de sulfato de cobre e de permanganato de potássio.

\section{Procedimentos:}

1 - Preparar soluções aquosas de sulfato de cobre $\left(\mathrm{CuSO}_{4}\right)$ e de permanganato de potássio $\left(\mathrm{KMnO}_{4}\right)$;

2 - Embeber uma porção de algodão em rama com água e colocá-la sobre o vidro de relógio:

3 - Fixar o algodão entre dois crocodilos e completar o circuito eléctrico;

4 - Colocar duas gotas de cada uma das soluções no ponto médio do algodão, de forma a não ficarem sobrepostas;

5 - Ligar a fonte e aumentar gradualmente a tensão, aguardando alguns minutos até ser observado o movimento de cada uma das manchas.

Observações: Observa-se que a mancha de cor violácea se deslocou em direcção ao pólo positivo, enquanto que a mancha azulada se deslocou em direcção ao polo negativo.

Interpretações: Na mistura líquida existem os catiões cobre $\left(\mathrm{Cu}^{2+}\right)$ e potássio $\left(\mathrm{K}^{+}\right)$, e os aniões sulfato $\left(\mathrm{SO}_{4}{ }^{2-}\right)$ e permanganato $\left(\mathrm{MnO}_{4}\right)$. Quando é aplicada a diferença de potencial às extremidades do algodão, é exercida sobre os vários iões uma força eléctrica que os faz movimentar-se em direcção ao terminal da fonte de sinal contrário ao da sua carga eléctrica. Deste modo, o movimento dos catiões será contrário ao dos aniões. Daqui resulta que os iões $\mathrm{Cu}^{2+}$ (coloração azul) e $\mathrm{K}^{+}$ (incolores) deslocar-se-ão em direcção ao pólo negativo, e os iões $\mathrm{SO}_{4}{ }^{2-}$ (incolores) e $\mathrm{MnO}_{4}^{-}$(coloração vio- 
lácea) deslocar-se-ão em direcção ao polo positivo.

A interpretacão das observações efectuadas na Experiência 1 leva-nos a admitir que nas soluções aquosas de sais, como os acima mencionados, o processo da condução eléctrica envolve o movimento orientado dos iões positivos e negativos em sentidos opostos.

Ao longo de um circuito eléctrico, o processo de condução nos metais difere do processo de condução nas soluções iónicas. Assim, enquanto que nos condutores metálicos a condução eléctrica pode ser explicada pelo movimento dos electrões num dado sentido, num condutor iónico este processo envolve o movimento dos catiões e aniões, em sentidos opostos.

Pelas considerações feitas até agora, podemos prever que, por exemplo, o cloreto de sódio sólido não conduza a corrente eléctrica, uma vez que as intensas forças electrostáticas existentes entre os seus iões constituintes impedem o estabelecimento de um fluxo de iões, quando sujeitos a um campo eléctrico. Contudo, tal fluxo já será possível se o cloreto de sódio se encontrar no estado fundido ou em solução.

Será que a capacidade de uma substância para originar uma solução condutora da corrente eléctrica está restrita aos compostos iónicos? E será que essa capacidade depende do solvente?

Para responder a estas duas questões, realizemos a Experiência 2 .

\section{EXPERIÊNCIA 2}

\section{Parte I}

Título: A condutibilidade eléctrica de algumas soluções aquosas.

Objectivo: Verificar que substâncias moleculares, como o ácido sulfúrico e o ácido acético, originam soluções aquosas condutoras da corrente eléctrica.

Material: Fonte de corrente; miliamperímetro; fios de ligação; crocodilos; eléctrodos de grafite; provetas.

Reagentes: Ácido sulfúrico concentrado; ácido acético concentrado; água destilada.

\section{Procedimentos:}

l - Montar o circuito eléctrico;

2 - Observar o comportamento do miliamperímetro quando um certo volume de água destilada é vertido no recipiente;

3 - Adicionar algumas gotas de ácido sulfúrico concentrado à água destilada é vertido no.recipiente;

4 - Observar o comportamento do miliamperímetro;

5 - Repetir a experiência com ácido acético concentrado.

Observações: Verifica-se que quando se adicionam os dois ácidos à água destilada o miliamperímetro detecta a passagem da corrente eléctrica.

Conclusões: Uma vez que tanto o ácido sulfúrico como o ácido acético produzem soluções aquosas condutoras da corrente, então estas duas substâncias moleculares adicionadas a água sofrem um processo de ionização.

\section{PARTE II}

Título: A condutibilidade eléctrica de soluções de cloreto de sódio em diferentes solventes.

Objectivo: Comparar a condutibilidade eléctrica de soluções de cloreto de sódio em vários solventes.

Material: Fonte de corrente; miliamperímetro; fios de ligação; crocodilos; eléctrodos de grafite; proveta; espátula.

Reagentes: Cloreto de sódio; água; álcool etílico; tricloroetano.

\section{Procedimentos:}

1 - Proceder à montagem do circuito eléctrico tal como na experiência acima;

2 - Verter um dado volume de água destilada para o recipiente inserido no circuito eléctrico;

3 - Adicionar, com a espátula, uma certa porção de cloreto de sódio à água, e registar o valor da intensidade da corrente lido no miliamperímetro:

4 - Repetir as operações para os outros solventes.

Observações: No caso dos solventes água e álcool etílico verificase que a adição de cloreto de sódio produz um aumento da intensidade da corrente. Quando o solvente usado é o tricloroetano, a adição de cloreto de sódio não produz qualquer variação na intensidade da corrente.

Conclusão: Estas experiências revelam que a capacidade do cloreto de sódio para produzir soluções condutoras da corrente eléctrica depende da natureza do solvente. Assim, podemos admitir que o cloreto de sódio origina soluções condutoras da corrente eléctrica unicamente no caso em que as moléculas do solvente são polares, tal como a água e o álcool etílico. Isto significa que estes dois solventes favorecem a dissociação iónica do cloreto de sódio, ao contrário do tricloroetano.

Substâncias que quando adicionadas a um solvente originam uma solução com maior condutibilidade eléctrica que a do solvente, designam-se por electrólitos. São exemplos o cloreto de sódio, o ácido sulfúrico e o ácido acético; as respectivas soluções aquosas designam-se por soluções electrolíticas.

\section{Agradecimento}

A autora aqradece ao Prof. Doutor Victor M.M. Lobo o apoio dado. 